\title{
Influence of Steel Impact Strength on the Maintenance and Operation of Civil Engineering Structures
}

\author{
Kamil Pawłowski, Agata Włóka, Wrocław University of Environmental and Life Sciences
}

\begin{abstract}
Steel structures are extremely susceptible to all material defects that may occur in the bearing elements. Material defects may result in local weakening or accumulations of stress that lead to the emergence of fractures and the propagation of cracks, which, in turn, may cause structural damage. The capability of steel to resist to cold cracking is referred to as impact strength. It is particularly important due to the course of disasters that may occur as a result of such a fracture. They are extremely rapid and thus may have very serious consequences as they do not leave sufficient time for evacuation. The paper discusses the analysis of historical steels in terms of the impact strength of steel used in bridge structures for a period exceeding a hundred years and the attempt to determine the influence of fatigue on the impact strength of steel. In order to determine this correlation, samples were collected from the truss structures of the main girders of bridge spans. Samples were collected from two sites on the structure: the lower chords of the main girders in the mid-span of the girder and from the support zone. Previously, the bridge steel had been subjected to tests of tensile strength, chemical composition and an initial test of impact strength of steel was conducted at a temperature of $-20^{\circ} \mathrm{C} ; 0^{\circ} \mathrm{C}$ and $+20^{\circ} \mathrm{C}$. The results were presented in papers [3]. The current article provides a much wider scope of tests, both in terms of the number of analysed samples and the differences in temperature. A total of 30 samples were tested at temperatures of $-60^{\circ} \mathrm{C},-40^{\circ} \mathrm{C}$, $-20^{\circ} \mathrm{C}, 0^{\circ} \mathrm{C}$ and $20^{\circ} \mathrm{C}$. The tests confirmed the initial hypothesis that fatigue influences the impact strength of steel. We have also succeeded in developing an impact strength curve for historical steels, which is different from that presented in the subject literature.
\end{abstract}

Keywords: impact strength, steel, bridges, fatigue load.

\section{Introduction}

Steel is currently widely used as a construction material in various types of structures, starting from residential buildings to industrial and transport structures. Both the steel manufacturing technology itself and the ways to use steel for erecting construction facilities have been developing for centuries. Various technological problems related to the application of steel were encountered. They included, among others, the influence of increased temperature on steel bearing capacity, sensitivity to dynamic loads, fatigue-related problems and brittle fractures. Many of these issues were successfully solved to a sufficient extent. However, new questions arise with the development of technology and the simultaneous ageing of existing structures. The authors of this paper decided to handle the issue related to the simultaneous occurrence of the influence of fatigue load of construction steel and the impact strength of steel, pursuant to the hypothesis of accumulating damages [1], [4]. The analysed steel was obtained from the structure of a railroad bridge that has been in operation for more than 100 years. A bridge, as a structure subjected to regular loads, is the perfect type of structure to be selected for the analysis of the accumulation of such influences. Historical steel, manufactured at the end of the $19^{\text {th }}$ century, is a very valuable research material, as it may provide an answer to the question of how to deal with historical structures in the event if it is necessary to repair or reinforce them. The paper presents the results of impact strength tests for samples collected from parts of the structure where the lowest and the highest fatigue-related influences occurred. The results of impact strength tests conducted at temperatures from $-60^{\circ} \mathrm{C}$ to $+20^{\circ} \mathrm{C}$ are presented. The results presented herein are a continuation of the research published in the paper [3], expanded by further temperatures of the steel work of fracture tests and the number of analysed samples. 


\section{Characteristics of the analysed object}

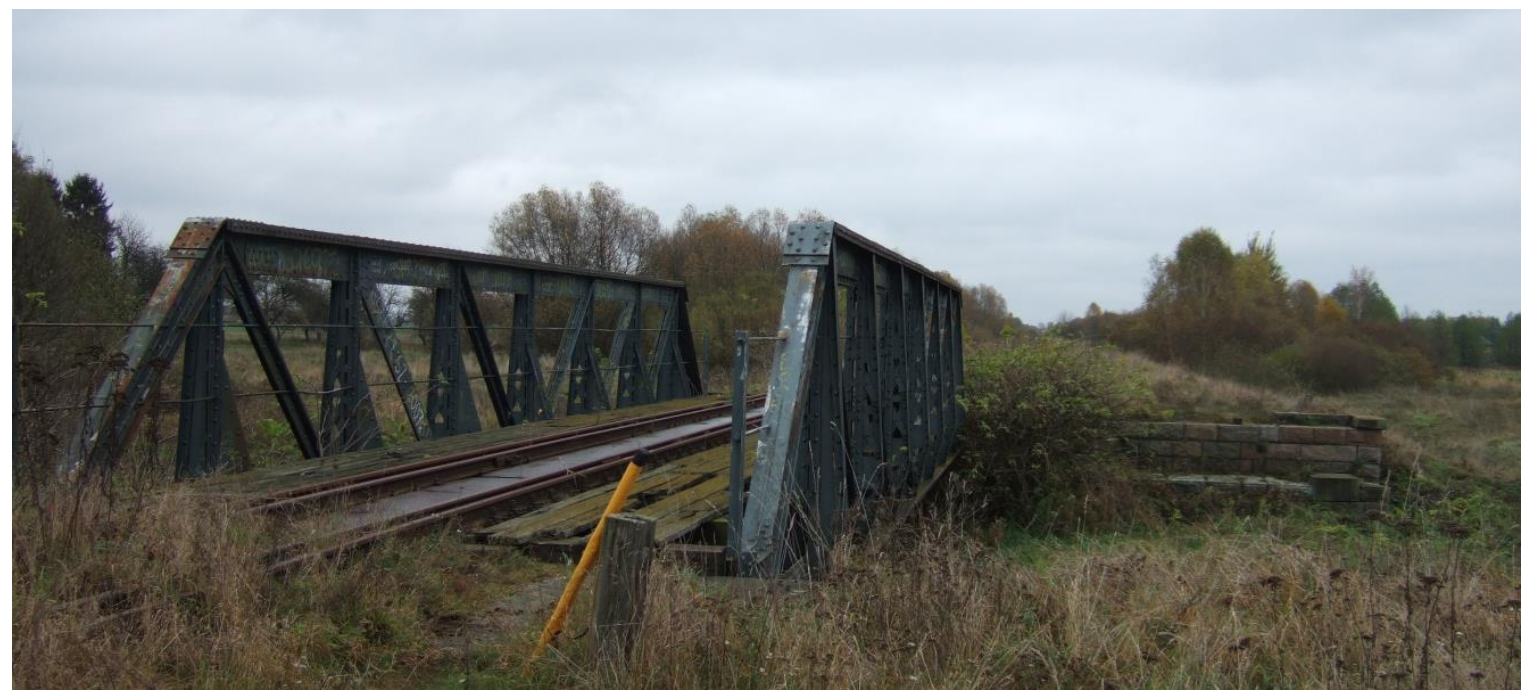

Fig. 1. A view of the railroad bridge at km 25.414 of line No. 30 Łuków- Lublin

The span of the bridge from which samples were collected for the analysis is located on the ŁukówLublin line No. 30, at km 25.414 (Fig. 1). The structure was erected at the end of the $19^{\text {th }}$ century, as part of the Łuków-Lublin railroad. The railway line was apparently constructed by the Russians and was of strategic importance for the Russian armed forces during World War I.

The object is a single-span steel structure based on simply supported beam design. The design is shown in Figure 2. The main girders of the object are two trusses of a theoretical span of $22.36 \mathrm{~m}$, with railroad tracks placed on beams of the bottom chord of the truss, which is a Pratt truss with parallel chords. Crossbars are placed at approx. $2.8 \mathrm{~m}$. The height of the trusses is $3.05 \mathrm{~m}$. The spacing between the main girders is $5.25 \mathrm{~m}$. Two sidebars with $1.83 \mathrm{~m}$ axial spacing are connected to the crossbars, stiffened with a vertical bracing in the middle of the truss span and horizontal bracings on the plane of the top and bottom chords.

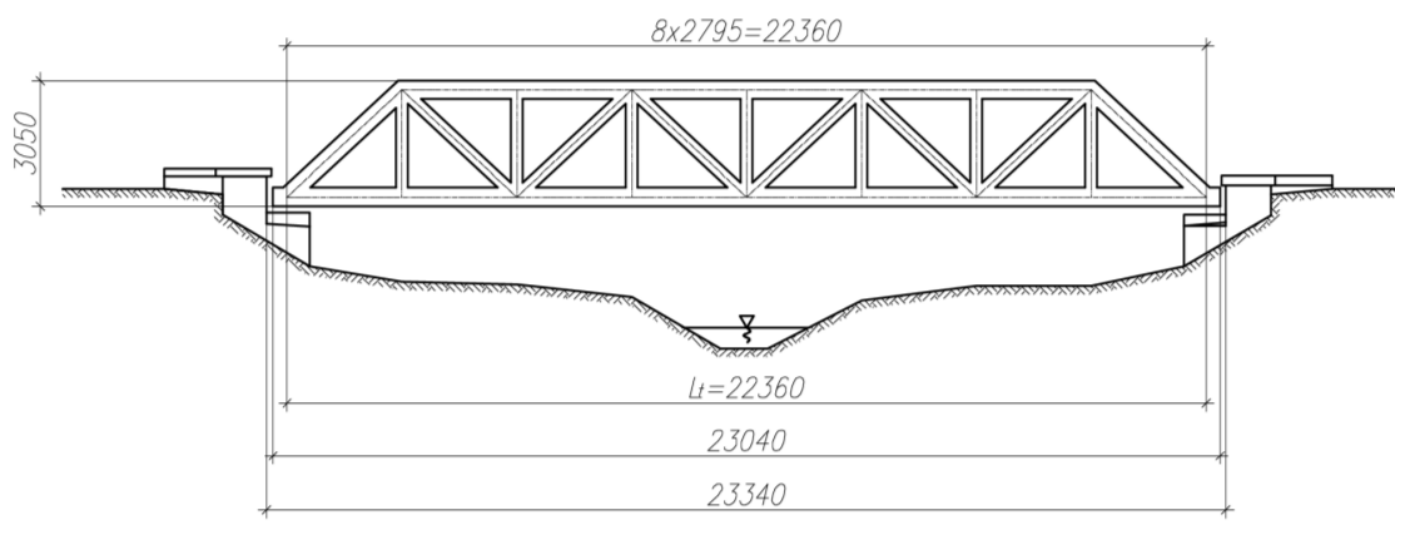

Fig. 2. Diagram of the bridge

The samples for analysis were collected from these elements of the bridge that were subjected to fatigue load to the lowest and highest extent during the operation of the bridge. Due to the static scheme of the simply supported beam, this was the zone in the middle of the span and at the supporting pillar. The samples of the highest fatigue load were collected from the sheet metal of the bottom chord of the truss, from the element marked as number 3 in Figure 3. The samples of the lowest fatigue load were cut from element number 1, shown in Figure 3. 

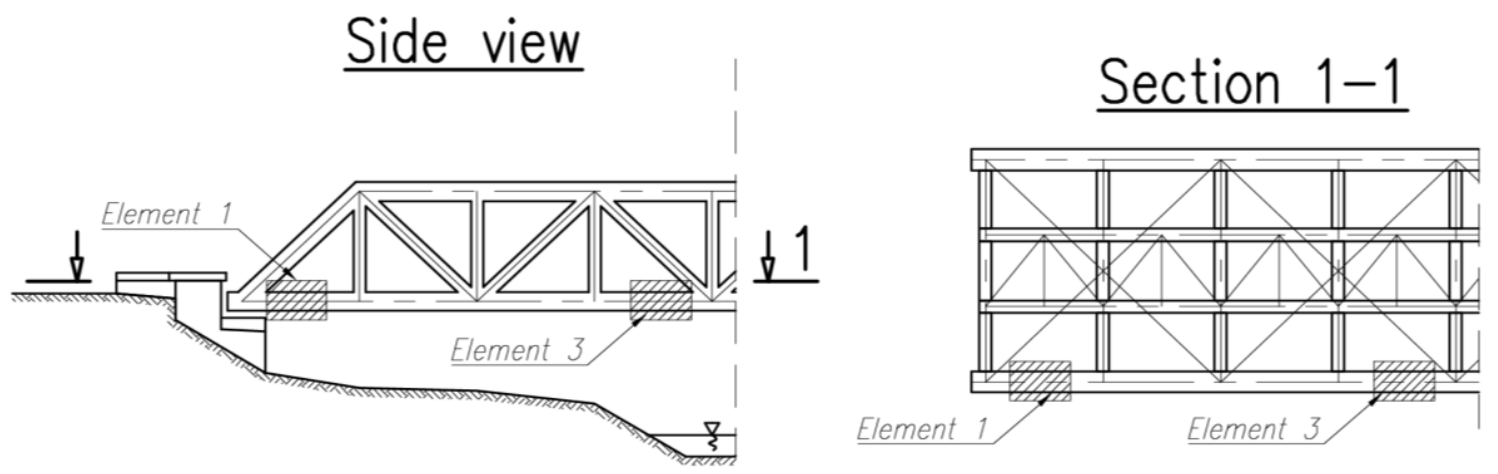

Fig. 3. Locations of elements from which samples were cut out for analysis

The authors' previously conducted tests, the results of which were published in paper [3], included the results of the analysis of basic mechanical properties of the analysed steel, chemical composition analysis and preliminary impact strength tests at temperatures ranging from $-20^{\circ} \mathrm{C}$ to $+20^{\circ} \mathrm{C}$. These results allowed us to determine the type of steel from which the bridge was constructed and confirmed the initial hypothesis concerning the influence of fatigue load on steel impact strength. Due to that, the authors decided to conduct further research and to expand the temperature range of impact strength tests. This refers mainly to temperatures below zero, which are much worse for the properties of construction steel.

\section{Research methodology}

Impact strength, which may be defined as the resistance of the material to fractures caused by impact, is also a measure of brittleness. This means that the more brittle the material, the lower its impact strength [2]. Both in the construction industry and in other fields of technology, certain minimal values of impact strength have been set for specific types of steel, depending on the stress of the structural element.

Impact strength tests are conducted in compliance with the PN-EN ISO 148-1 standard [6], on samples with notches of a standardised shape and dimensions, supported on both ends (Figure 4). The standard foresees two types of samples, with $\mathrm{V}$ and $\mathrm{U}$ shaped notches. The analysed samples should have a square cross-section of the dimensions $8 \times 8 \mathrm{~mm}$. Impact strength tests are performed with the use of equipment that enables one to apply a high force in a short time, usually called impact hammers. The most commonly used device is the Charpy hammer.

Sections of material from which test samples are then collected should be cut cold using a moulder or cutter. At the same time, attention should be paid to local overheating of the sample or potential cold compression of the material that might negatively affect the impact strength test. For example, the sample may be cut using an acetylene burner, but adequate excess should be then foreseen, which will then be removed while cutting a normalised dimension sample. The number of samples is specified by the aforementioned standard [6]. Samples should be completely chip processed only in specific cases one edge may be left unprocessed. The notch on the sample is created by milling, drilling or cutting. The notch surface should be free from any cracks or fractures. All dimensions of the notch, such as its depth, edge opening angle, or the radius of the rounding of notch bottom are precisely defined in the reference standard [6] as they have a considerable influence on the obtained results. 

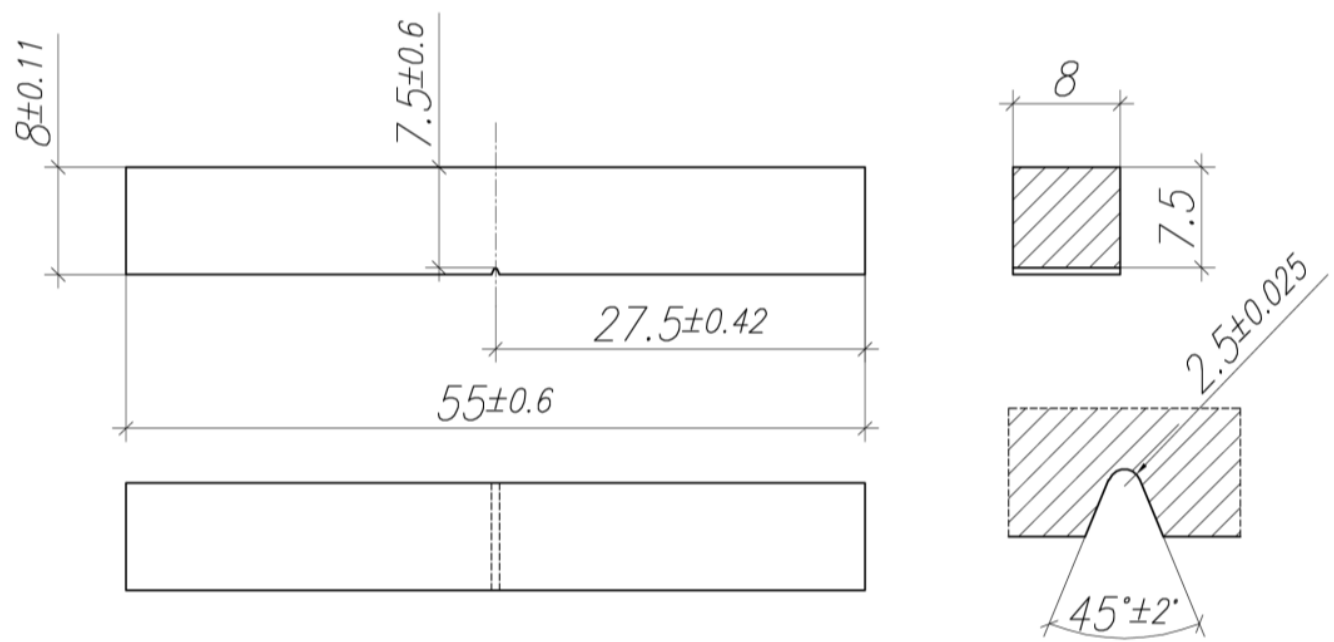

Fig. 4. Sample for Charpy impact strength testing

\section{Results of steel impact strength tests}

Steel impact strength tests were ordered to be conducted at a specialist laboratory at the Batory Steel Works in Chorzow. The test was conducted with the use of a Charpy hammer. The results of the work of fracture for the steel samples collected from the element subject to low fatigue load are presented in Table 1 and in the diagram in Figure 5. The analysis of the results mentioned above demonstrates that although the analysed steel should not be characterised by high fatigue use, its work of fracture is very low. This is even more important as the bridge structure is exposed to very low working temperatures, even below $-30^{\circ} \mathrm{C}$. The obtained results disqualify this steel as a construction material. The $27 \mathrm{~J}$ value that has to be met in order to consider the steel as construction material is achieved only at the temperature of $0^{\circ} \mathrm{C}$ for the analysed element. Thus, pursuant to the binding reference standards, this steel should be classified as $\mathrm{J} 0$. However, considering that the presented work of fracture values are characteristic values, after statistical processing of the results it might turn out that this steel may be classified as JR steel, i.e. such steel, for which the impact energy requirement is met at $+20^{\circ} \mathrm{C}$.

TABLE 1

Results of work of fracture tests for samples collected from element 1

\begin{tabular}{|l|c|c|c|c|c|}
\hline & \multicolumn{5}{|c|}{ Element 1 } \\
\hline Temperature & $-60^{\circ} \mathrm{C}$ & $-40^{\circ} \mathrm{C}$ & $-20^{\circ} \mathrm{C}$ & $0^{0} \mathrm{C}$ & $20^{\circ} \mathrm{C}$ \\
\hline \hline Work of fracture & {$[\mathrm{J}]$} & {$[\mathrm{J}]$} & {$[\mathrm{J}]$} & {$[\mathrm{J}]$} & {$[\mathrm{J}]$} \\
\hline \hline Sample 1 & 3 & 7 & 31 & 34 & 44 \\
\hline Sample 2 & 4 & 5 & 14 & 36 & 39 \\
\hline Sample 3 & 4 & 6 & 10 & 28 & 36 \\
\hline \hline Average & 3.63 & 5.94 & 16.31 & 32.48 & 39.53 \\
\hline Population standard deviation $=\sqrt{\frac{\sum(x-\bar{x})^{2}}{n}}$ & 0.47 & 0.82 & 9.10 & 3.40 & 3.30 \\
\hline Sample standard deviation $=\sqrt{\frac{\sum(x-\bar{x})^{2}}{(n-1)}}$ & 0.6 & 1.0 & 11.2 & 4.2 & 4.0 \\
\hline Square deviation $=\sum(x-\bar{x})^{2}$ & 0.67 & 2.00 & 248.67 & 34.67 & 32.67 \\
\hline
\end{tabular}




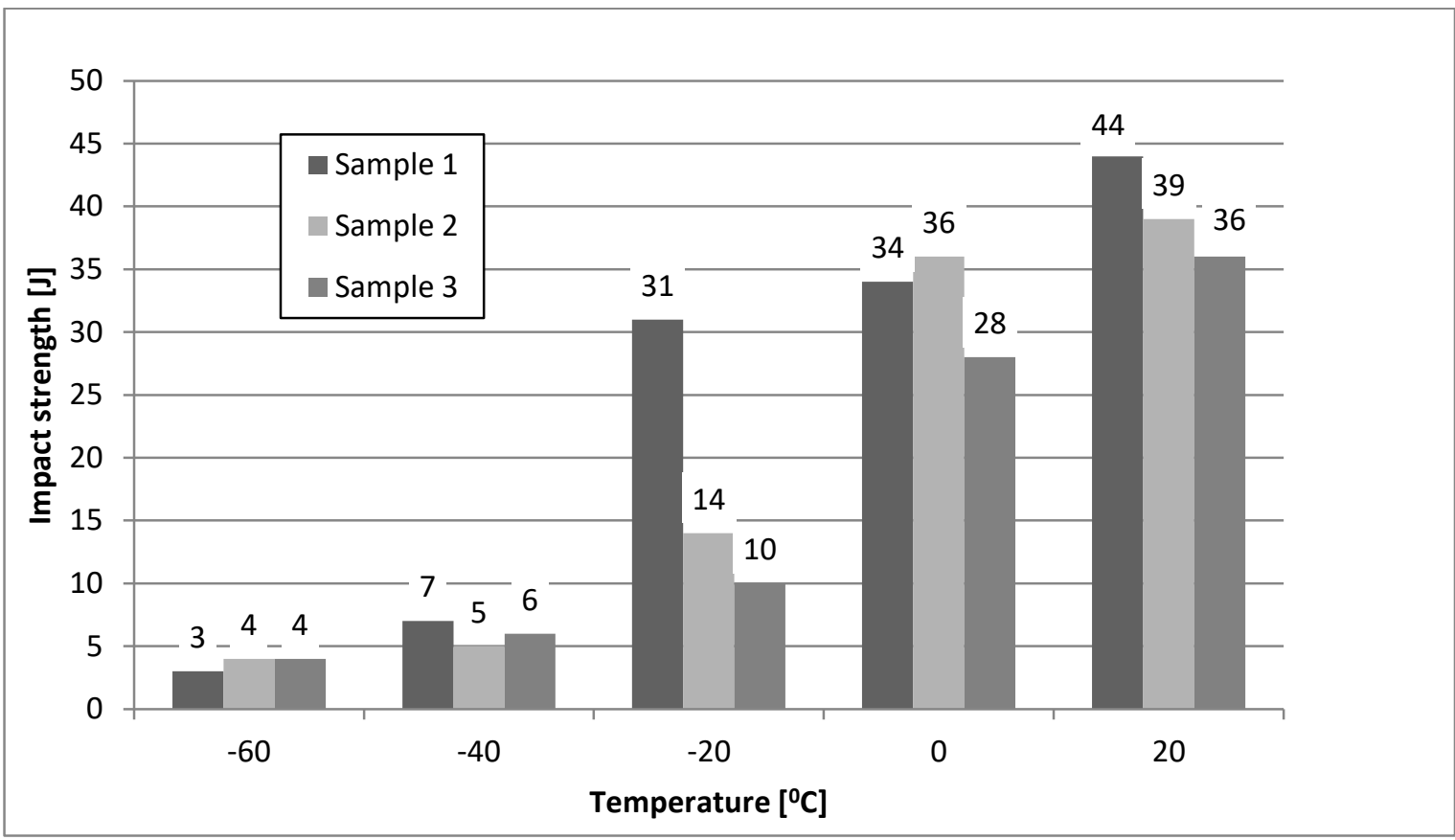

Fig. 5. Diagram illustrating the relation between the work of fracture KV and temperature

Table 2 and Figure 6 show the analogical test results for the samples collected from the element, where the fatigue load was significant, i.e. from the element of the bottom chord of the truss in the middle of its span. One may easily notice that the values of fracture work are much lower than those of element 1. For this element, only at $+20^{\circ} \mathrm{C}$ the fracture work for $\mathrm{V}$-notch sample exceeds 27J. However, this increase is very significant in comparison to the other obtained results, and one may expect that it is caused by a material anomaly at the location from which samples were collected. In this case, steel cannot be considered as safe to be used in the structure of a bridge, either.

TABLE 2

Results of fracture work tests for samples collected from element 3

\begin{tabular}{|l|c|c|c|c|c|}
\hline & \multicolumn{5}{|c|}{ Element 3 } \\
\hline Temperature & $-60^{0} \mathrm{C}$ & $-40^{0} \mathrm{C}$ & $-20^{0} \mathrm{C}$ & $0 \mathrm{C}$ & $20^{0} \mathrm{C}$ \\
\hline \hline Work of fracture & {$[\mathrm{J}]$} & {$[\mathrm{J}]$} & {$[\mathrm{J}]$} & {$[\mathrm{J}]$} & {$[\mathrm{J}]$} \\
\hline \hline Sample 1 & 3 & 4 & 18 & 24 & 60 \\
\hline Sample 2 & 3 & 4 & 4 & 12 & 86 \\
\hline Sample 3 & 3 & 5 & 6 & 14 & 54 \\
\hline Average & 3.00 & 4.31 & 7.56 & 15.92 & 65.32 \\
\hline Population standard deviation $=\sqrt{\frac{\sum(x-\bar{x})^{2}}{n}}$ & 0.00 & 0.47 & 6.18 & 5.25 & 13.89 \\
\hline Sample standard deviation $=\sqrt{\frac{\sum(x-\bar{x})^{2}}{(n-1)}}$ & 0.0 & 0.6 & 7.6 & 6.4 & 17.0 \\
\hline Square deviation $=\sum(x-\bar{x})^{2}$ & 0.00 & 0.67 & 114.67 & 82.67 & 578.67 \\
\hline
\end{tabular}


DEVELOPMENT 17" Proceedings "CIVIL ENGINEERING"17"

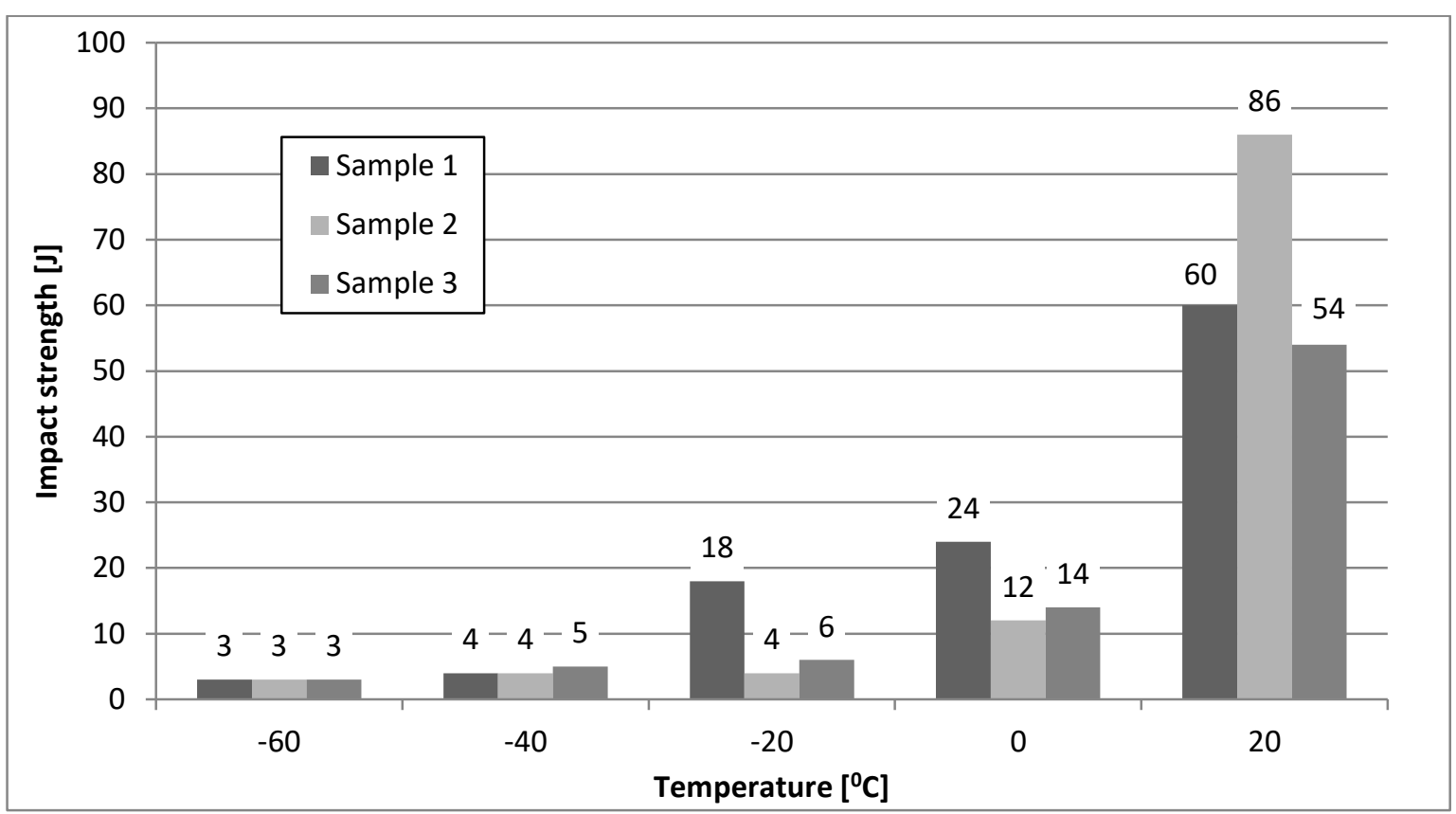

Fig. 6. Diagram illustrating the relation between the work of fracture KV and temperature for samples subjected to fatigue.

The comparison of results is shown in the diagram in Figure 7. The lines reflect the so-called impact strength curves of steel. These curves may be compared to those discussed in the literature. As far as their shape is concerned, it is similar to that of curves presented in other sources [6]. However, it differs by the fact that it does not become flat within the temperature range below $-20^{\circ} \mathrm{C}$, as it may have been expected according to the existing state of knowledge, but the fracture work values continue to decrease to $-40^{\circ} \mathrm{C}$. The work of the fracture values for steel subjected to fatigue are considerably lower than those obtained for steel not subjected to fatigue.

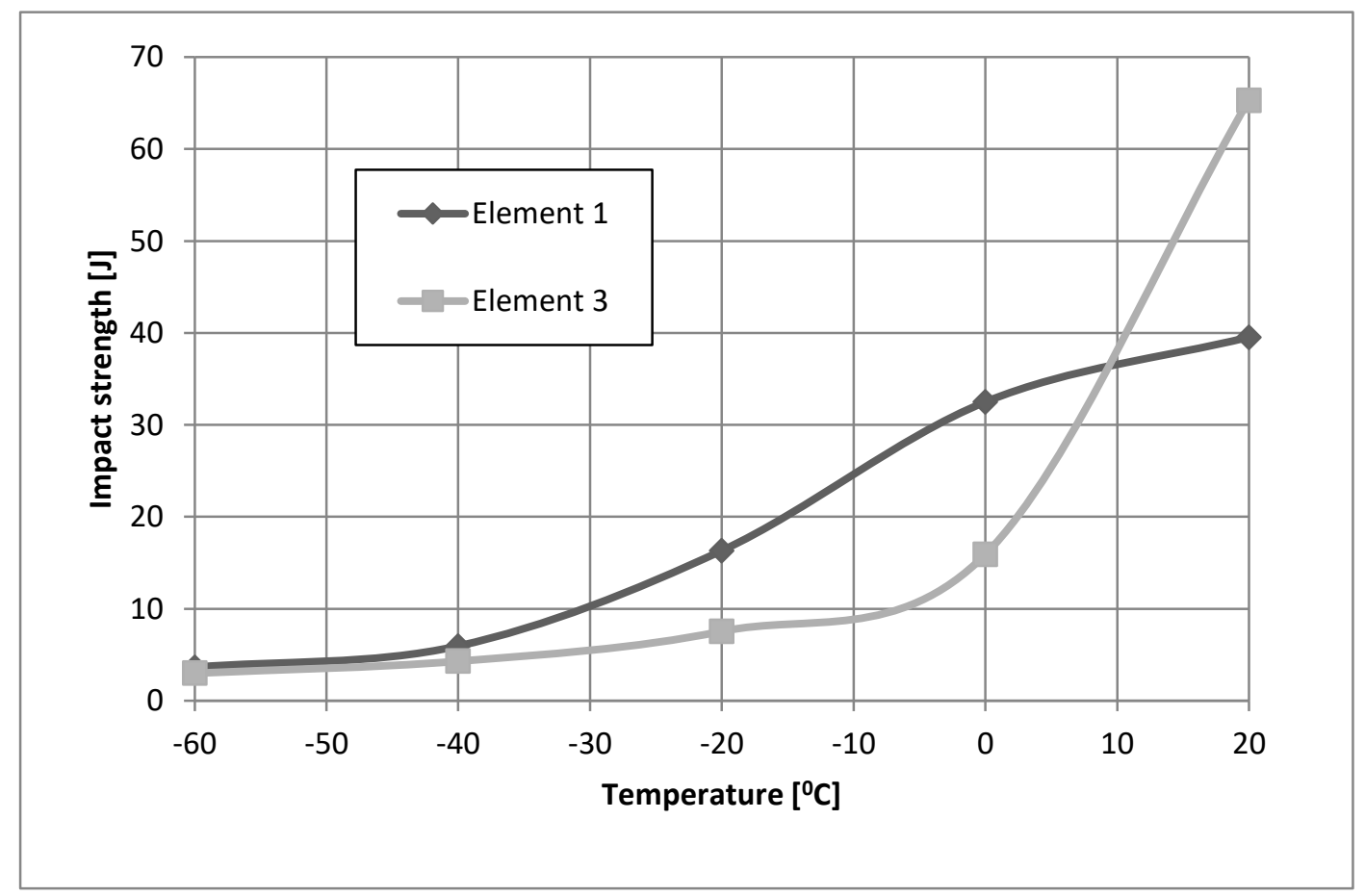

Fig. 7. Steel impact strength curves for samples subjected and not subjected to fatigue. 


\section{Conclusions}

The analysis of the results presented in this paper demonstrates that the work of structure of historical steels at low temperatures does not meet the requirements defined for today's construction steel. The work of fracture should be no less than 27J. The authors managed to confirm the hypothesis that elements subjected to higher load are characterised by a lower work of fracture at low temperatures, due to fatigue. Historical types of steel are very brittle, consequently the structures made from such steel are even more prone to sudden failures. This applies in particular to such objects as bridges, which are additionally exposed to the effects of material fatigue. It was also observed that the lowering in the yield strength of steel resulting from fatigue also influences the decrease in the value of the work of fracture KV.

\section{References}

1. Augustyn J., Śledziewski E. Awarie konstrukcji stalowych. Warszawa: Arkady, 1976, 210 p.

2. Gosowski, B., Kubica, E. . Badania laboratoryjne z konstrukcji metalowych. Wrocław: Oficyna Wydawnicza, 2007, p.33-41

3. Pawłowski, K., Włóka, A. Influence of impact strength of steel on the repair and usage possibilities of civil engineering structures. 7th International Conference on Safety and Durability of Structures ICOSADOS 2016. May 10 - 12, 2016, UTAD, Portugal

4. Rykaluk, K. Pęknięcia w konstrukcjach stalowych. Wrocław: DWE, 2000. 231 p.

5. Wyrzykowski, J.W., Pelszakow, E. , Sieniawski, J. Odksztatcenia i pękanie metali. Warszawa: WNT, 1999, 404 p.

6. PN-EN ISO 148-1:2017-02 Metale - Próba udarności sposobem Charpy'ego -- Część 1: Metoda badania 